\title{
Development of a replicable oriC plasmid for Mycoplasma gallisepticum and Mycoplasma imitans, and gene disruption through homologous recombination in M. gallisepticum
}

\author{
Correspondence \\ P. F. Markham \\ pmarkham@unimelb.edu.au
}

Received 9 April 2008

Revised 8 June 2008

Accepted 9 June 2008

\author{
S.-W. Lee, G. F. Browning and P. F. Markham \\ School of Veterinary Science, The University of Melbourne, Parkville, Victoria 3010, Australia
}

\section{INTRODUCTION}

Mycoplasma gallisepticum is an important pathogen of poultry, causing chronic respiratory disease in chickens and infectious sinusitis in turkeys. It is responsible for considerable economic losses in poultry production worldwide due to downgrading of carcasses, reduced feed conversion efficiency, decreased egg production and increased medication costs (Ley \& Yoder, 1997). Recently the genome of $M$. gallisepticum was sequenced completely (Papazisi et al., 2003), allowing prediction of the function of specific genes. However, genetic studies of M. gallisepticum have been limited by the lack of genetic tools for its manipulation, with most studies using transposons Tn916 (Dybvig \& Cassell, 1987; Dybvig \& Alderete, 1988; Whetzel et al., 2003) and Tn4001 (Bearson et al., 2003; Hedreyda et al., 1993; Hudson et al., 2006; Mahairas \& Minion, 1989; Mudahi-Orenstein et al., 2003; Papazisi et al., 2002; Whetzel et al., 2003; Winner et al., 2003) or suicide vectors (Markham et al., 2003) to study gene function. However, the random insertion of the transposon in the genome of

The GenBank/EMBL/DDBJ accession number for the oriC region sequence of M. imitans is EF028085. the organism does not allow specific targeting of a gene of interest, and random integration can confound analyses of gene expression (Dybvig \& Cassell, 1987; Mahairas \& Minion, 1989). There has been some success in development of vectors for mollicutes using homologous origins of replication (oriC) and selectable antibiotic resistance markers. These plasmids are able to replicate extrachromosomally and have been used to inactivate target genes by homologous recombination (Cordova et al., 2002; Duret et al., 1999; Janis et al., 2005; Lartigue et al., 2002). In many cases oriC plasmids containing larger oriC regions have been found to integrate into the oriC region in the genomic DNA by homologous recombination following in vitro passage. Plasmids containing a shorter oriC region are more stable and have been used to generate targeted homologous recombination (Cordova et al., 2002; Lartigue et al., 2002; Renaudin et al., 1995). Most of the oriC plasmids of mollicutes show host specificity, but plasmids containing the oriC of Mycoplasma mycoides subsp. mycoides LC and SC replicate in the closely related species Mycoplasma capricolum subsp. capricolum (Lartigue et al., 2003). Mycoplasma imitans, which has been isolated from ducks and geese, is phylogenetically closely related to M. gallisepticum. DNA-DNA hybridization studies show 
that M. gallisepticum and M. imitans share $40-46 \%$ genetic identity (Bradbury et al., 1993), whilst PFGE and random amplified polymorphic DNA studies suggest a DNA sequence identity of 53-60\% (Bradbury et al., 1993; Marois et al., 2001). Papazisi et al. (2003) reported that the predicted oriC region of $M$. gallisepticum was located between the dnaN and dnaA genes. The predicted oriC region contains five DnaA box sequences, with the consensus sequence $5^{\prime}$-TTWTMHAMA-3' identical for each DnaA box, and the region between $d n a N$ and soj contains a higher than average content of adenosine and thymidine $(80 \%)$. However, the DNA sequence of the $M$. imitans oriC region has not been determined. The aims of this study were to determine the DNA sequence of the $M$. imitans oriC region and to produce vectors containing different regions of the oriC of M. gallisepticum and $M$. imitans to assess their replication and stability during passage. We also attempted to inactivate a target gene in M. gallisepticum using these oriC plasmids. We chose to knockout the expressed VlhA1.1 gene of M. gallisepticum as the genome sequence is available and the target gene is not essential for the survival of the organism (Glew et al., 2000).

\section{METHODS}

Bacterial strains and growth media. M. gallisepticum strain S6 (Markham et al., 1992) and M. imitans strain 4229 (Bradbury et al., 1993) were grown in modified Frey's medium to late exponential phase at $37{ }^{\circ} \mathrm{C}$ (Whithear, 1993). Mycoplasma pneumoniae strain $\mathrm{FH}$ (ATCC No. 15531) (donated by V. Peters, Department of Virology, Royal Children's Hospital, Melbourne) was grown in modified Hayflick's medium in tissue-culture flasks. For the growth and selection of antibiotic-resistant mycoplasma transformants, tetracycline was added to a concentration of $4 \mu \mathrm{g} \mathrm{ml}^{-1}$ in broth or agar medium (Markham et al., 2003). Escherichia coli strain $\mathrm{DH} 5 \alpha$ was used as the host for gene cloning and was grown in Luria-Bertani (LB) broth at $37{ }^{\circ} \mathrm{C}$ and subjected to standard molecular biological techniques (Sambrook \& Russell, 2001).

\begin{abstract}
Amplification and DNA sequencing of the oriC region of $\boldsymbol{M}$. imitans strain 4229. Part of the oriC region and the $d n a A$ gene of $M$. imitans was amplified using the primer pairs SW15for and MIsojrev-1, and SW6for and dnaArev, respectively (Table 1), and cloned into pGEM-T for DNA sequencing. The remainder of the oriC region was sequenced directly from genomic DNA. The DNA sequence was aligned with the homologous region from the complete genome of M. gallisepticum strain $\mathrm{R}_{\text {low }}$ (GenBank accession no. NC_004829).
\end{abstract}

Table 1. Oligonucleotides used in this study

\begin{tabular}{|c|c|c|}
\hline Oligonucleotides & Sequence $^{\star}\left(5^{\prime}-3^{\prime}\right)$ & PCR product \\
\hline SW4 for/SW5 rev & $\begin{array}{l}\text { GAGCTTTTGCATGCAAAAAATTTC/ } \\
\text { TTGTTAATCCATGGAATGATCATAA }\end{array}$ & Long oriC region (LoriC; $1.96 \mathrm{~kb}$ ) \\
\hline SW6 for/SW7 rev & $\begin{array}{l}\text { CCTCAGCTGCAGTAGGTTATG/ } \\
\text { GAACTGAAATGTCGACTAAAAATC }\end{array}$ & Short oriC region (SoriC; $0.67 \mathrm{~kb}$ ) \\
\hline SW4 for/SW7 rev & & Whole oriC region (WoriC; $3.16 \mathrm{~kb}$ ) \\
\hline SW4 for/SW9 rev & /CTGATGCCGTTAGCATTAGG & Partial LoriC $1(1.06 \mathrm{~kb})$ \\
\hline SW15 for/SW16 rev & $\begin{array}{l}\text { CGCTTTAATATTGTAACAATA/ } \\
\text { GCTGTTATTCAAGAATAATAAATTC }\end{array}$ & Partial LoriC 2 (565 bp) \\
\hline SW4 for/PLori-rev-2 & /CAGATAGACAAAAGAATGAAAAAG & Partial LoriC 3 (707 bp) \\
\hline Start DnaN f/PLori-rev-2 & GATAAATCTGTGGATAACTC/ & Partial LoriC 4 (633 bp) \\
\hline SW4 for/PLori-rev-4 & /CACAATATTTCCGATAAAAATCAC & Partial LoriC 5 (510 bp) \\
\hline SW4 for/PLori-rev-5 & /TTTTACAAACAATATTGTTAC & Partial LoriC 6 (459 bp) \\
\hline SW4 for/PLori-rev-6 & /ACACGTTTTTGTGAAAAAGTGA & Partial LoriC 7 (180 bp) \\
\hline SW4 for/pPLoriC8rev & /GAGTTATCCTCTGATTTATC & Partial LoriC 8 (96 bp) \\
\hline pPLoriC9for/PLori-rev-6 & CCATGATAATTGTTGATAAATC/ & Partial LoriC 9 (119 bp) \\
\hline Tetfor/Tetrev & $\begin{array}{l}\text { GAAAAGATCTGGAGTAATTGGAAG/ } \\
\text { ACTAGTCCATATTTATATAACAACTT }\end{array}$ & Tetracycline resistance gene $(2.36 \mathrm{~kb})$ \\
\hline AmpR for/AmpR rev & $\begin{array}{l}\text { CCAATGCTTAATCAGTGAGG/ } \\
\text { GTATGAGTATTCAACATTTCCG }\end{array}$ & Ampicillin resistance gene (862 bp) \\
\hline SW6 for/dnaA rev & /AAGCATGTCTTAAAGTCTAATTAGAA & dnaA gene of $M$. imitans $(2.1 \mathrm{~kb})$ \\
\hline SW15 for/MIsoj rev-1 & /TTTTCCATTTTGTTTATTCTC & partial oriC region and soj gene of $M$. imitans $(2 \mathrm{~kb})$ \\
\hline MIdnaN for/MIsoj rev-2 & $\begin{array}{l}\text { CAGAAGAGAAGTTGCTTGAAAAC/ } \\
\text { CTAGTGTCGTCTTCAAAACAC }\end{array}$ & oriC region of $M$. imitans $(2.3 \mathrm{~kb})$ \\
\hline P3.03-F-SphI/P3.03-R-NcoI & $\begin{array}{l}\text { CTTTAGCTGCATGCGCAGATTCG/ } \\
\text { TTTTCCATGGGTTTTGCTTGG }\end{array}$ & Internal fragment of the vlhA3.03 gene $(1 \mathrm{~kb})$ \\
\hline P3.03-F-PstI/P3.03-R-SalI & $\begin{array}{l}\text { CTTTAGCTCCATCTGCAGATTCG/ } \\
\text { CATTAGGTTTTGCGTCGACGTTTAATG }\end{array}$ & Internal fragment of the vlhA3.03 gene $(1 \mathrm{~kb})$ \\
\hline SW13 for/vlhALeader rev & $\begin{array}{l}\text { CGACTCACTATAGGGCGAA/ } \\
\text { CAAATGAACCAATACCTAATAA }\end{array}$ & Integration site of $\mathrm{pMIoriC} / \Delta 3.03$ \\
\hline
\end{tabular}

${ }^{\star}$ Underlined bases are restriction endonuclease cleavage sites. 
Construction of oriC plasmids. Several regions of the predicted oriC region of $M$. gallisepticum were amplified by PCR (Fig. 1a). The long oriC region, the short ori $C$ region, and the whole ori $C$ region were amplified with the specific primer pairs SW4for and SW5rev, SW6for and SW7rev, and SW4for and SW7rev, respectively (Table 1). Each PCR contained $5 \mu \mathrm{l} 10 \times$ reaction buffer (Invitrogen), $10 \mu \mathrm{M}$ each deoxynucleoside triphosphate, $2.5 \mathrm{mM} \mathrm{MgSO}_{4}, 12.5 \mu \mathrm{M}$ each primer, $1.25 \mathrm{U}$ Platinum Taq High Fidelity DNA polymerase (Invitrogen), $10 \mathrm{ng}$ genomic DNA of M. gallisepticum strain $\mathrm{R}_{\text {low }}$ as template, and water to a final volume of $50 \mu$ l. PCRs were performed in a thermocycler (iCycler, Bio-Rad) under the following conditions: $94{ }^{\circ} \mathrm{C}$ for $4 \mathrm{~min}$, followed by 35 cycles of $94{ }^{\circ} \mathrm{C}$ for $30 \mathrm{~s}, 45^{\circ} \mathrm{C}$ for $2 \mathrm{~min}$, and $68{ }^{\circ} \mathrm{C}$ for $4 \mathrm{~min}$, with a final extension at $68{ }^{\circ} \mathrm{C}$ for $7 \mathrm{~min}$. PCR products were separated by agarose gel electrophoresis and extracted from gel slices using the QIAEX II kit (Qiagen) according to

(a)
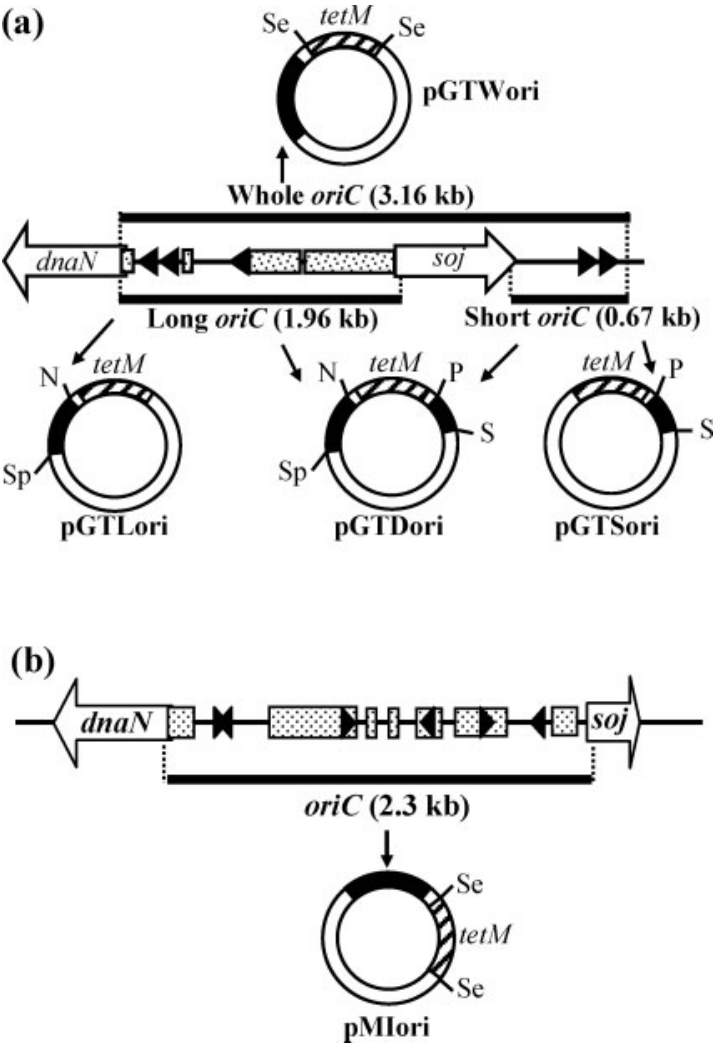

Fig. 1. Construction of $M$. gallisepticum and $M$. imitans oriC plasmids. (a) M. gallisepticum genomic oriC region and plasmid constructs containing different oriC regions. The plasmid backbone was PGEM-T (Promega) containing the tetracycline-resistance gene (tet $M)$. The long oriC region was inserted between the Sphl and Ncol sites located in the multicloning site of pGEM-T, and the short oriC was inserted between the Pstl and Sall sites. The whole oriC region was amplified by PCR and cloned into pGEM-T, and the tetM gene was then cloned into the Spel site. (b) $M$. imitans genomic oriC region and plasmid construct containing the oriC region. The oriC region was amplified and cloned into pGEM-T and then the tetM gene was cloned into the Spel site. The black triangles indicate the locations of the DnaA box consensus sequences and shaded rectangles indicate the locations of AT-rich clusters. Sp, Sphl; N, Ncol; P, Pstl; S, Sall; Se, Spel. the manufacturer's instructions. The long and short oriC regions were cloned separately into pGEM-T (Promega), into which the tetracycline-resistance gene had already been inserted (tetM/pGEM-T) (Markham et al., 2003). The long oriC region was inserted between the SphI and NcoI cleavage sites, and the short oriC region was inserted between the PstI and SalI sites (Fig. 1a). The resulting constructs were designated pGTLori and pGTSori. A further construct was produced that contained both the regions upstream and downstream from the soj gene, and was named pGTDori. The whole oriC region was amplified similarly and cloned into pGEM-T, and the tet $M$ gene was then cloned into the SpeI site of the vector, resulting in pGTWori (Fig. 1a). The oriC region of $M$. imitans was amplified from the genome of $M$. imitans strain 4229 using the MIdnaNfor and MIsojrev-2 primer pair (Table 1), introduced into the cloning site of pGEM-T, and the tet $M$ gene was then ligated into the SpeI cleavage site of the vector (Fig. 1b). To determine the minimal oriC region for plasmid replication in M. gallisepticum, different regions upstream of the soj gene were amplified by PCR with specific primer pairs (Table 1). To generate the oriC plasmids containing the PCR products shown in Fig. 2, each PCR product was cloned separately into pGEM-T, and the tet $M$ gene was then ligated into the SpeI site of the vector.

Transformation of $M$. gallisepticum strain S6, M. imitans strain 4229 and $\boldsymbol{M}$. pneumoniae strain FH. M. gallisepticum strain S6, $M$. imitans strain 4229 and M. pneumoniae strain $\mathrm{FH}$ were transformed by electroporation, as described by Hedreyda et al. (1993). Briefly, $5 \mathrm{ml}$ cultures of mycoplasmas were grown to late exponential phase and harvested by centrifugation at $12000 \mathrm{~g}$ for $5 \mathrm{~min}$ in a bench-top centrifuge at room temperature. The cells were washed twice in $250 \mu \mathrm{l}$ ice-cold HEPES-sucrose buffer ( $8 \mathrm{mM}$ HEPES, $272 \mathrm{mM}$ sucrose, $\mathrm{pH}$ 7.4). The cell pellet was then resuspended in $100 \mu \mathrm{l}$ HEPESsucrose buffer containing $\sim 10 \mu \mathrm{g}$ plasmid DNA and transferred to a Gene Pulser cuvette with a $0.2 \mathrm{~cm}$ electrode gap (Bio-Rad), and the mixture was pulsed using a Gene Pulser (Bio-Rad) set at $2.5 \mathrm{kV}, 100 \Omega$ and $25 \mu \mathrm{F}$. The cells were resuspended in $1 \mathrm{ml}$ broth and incubated at $37{ }^{\circ} \mathrm{C}$ until the medium showed a colour change, after which $500 \mu \mathrm{l}$ culture was plated onto agar medium containing $4 \mu \mathrm{g}$ tetracycline $\mathrm{ml}^{-1}$. The plates were incubated at $37{ }^{\circ} \mathrm{C}$ for $7-10$ days in the dark in an airtight jar for M. gallisepticum and M. imitans, and incubated for 21 days for M. pneumoniae. Individual tetracycline-resistant colonies

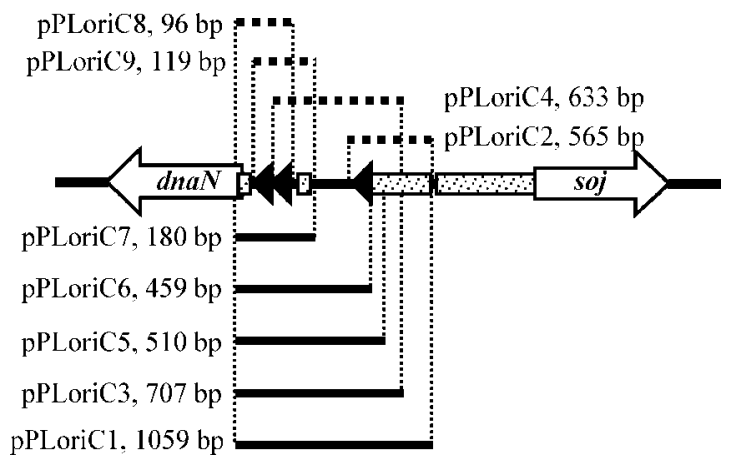

Fig. 2. Schematic representation of reduced oriC regions amplified by PCR and cloned into PGEM-T. The solid lines indicate the PCR products which generated plasmids that could be detected following transformation of M. gallisepticum, while the dashed lines indicate those that generated plasmids that could not be detected in $M$. gallisepticum. Black triangles indicate DnaA boxes and shaded rectangles indicate AT-rich clusters. 
were selected and subcultured in $1 \mathrm{ml}$ broth containing $4 \mu \mathrm{g}$ tetracycline $\mathrm{ml}^{-1}$ and incubated until the medium changed colour. To confirm the presence of the plasmid, tet $M$ was amplified by PCR with the Tetfor and Tetrev primer pair (Table 1). Transformants were passaged by inoculating $1 \mathrm{ml}$ late-exponential-phase culture into $19 \mathrm{ml}$ broth containing $4 \mu \mathrm{g}$ tetracycline $\mathrm{ml}^{-1}$.

Southern blot analysis. M. gallisepticum strain S6 and M. imitans strain 4229 genomic DNA, and oriC plasmid DNA were digested to completion with the restriction endonuclease Nsil (New England Biolabs). The fragments were separated in a $0.7 \%$ agarose gel and blotted onto Hybond- ${ }^{+}$membranes (Amersham). The DNA was fixed to the membrane by exposure to UV light for $5 \mathrm{~min}$ and the blot was prehybridized in a buffer containing $7 \%$ SDS, $1 \%$ BSA, $1 \mathrm{mM}$ EDTA and $0.25 \mathrm{M} \mathrm{Na}_{2} \mathrm{HPO}_{4}\left(\mathrm{pH}\right.$ 7.2) for $2 \mathrm{~h}$ at $58{ }^{\circ} \mathrm{C}$ (Church \& Gilbert, 1984). A probe containing $50 \mathrm{ng}$ of a $1.96 \mathrm{~kb}$ PCR product produced with the primer pair SW4for and SW5rev was radiolabelled with $\left[\gamma_{-}{ }^{32} \mathrm{P}\right]$ ATP using a random-primed DNA labelling kit (Roche). Unincorporated nucleotides were removed by passage through a BioSpin 30 chromatography column (Bio-Rad), following the manufacturer's instructions. The radiolabelled probe was denatured by incubation at $100{ }^{\circ} \mathrm{C}$ for $10 \mathrm{~min}$ and then added to the hybridization buffer and incubated with the membrane at $58{ }^{\circ} \mathrm{C}$ overnight. The next day the membrane was washed three times in $2 \times \operatorname{SSC}(0.3 \mathrm{M}$ $\mathrm{NaCl}, 30 \mathrm{mM}$ sodium citrate, $\mathrm{pH} 7.0$ ), $0.1 \% \mathrm{SDS}$ at $58{ }^{\circ} \mathrm{C}$ for $20 \mathrm{~min}$ each. The membrane was autoradiographed at room temperature overnight on BioMax film (Kodak). The same method was used to produce probes to detect the ampicillin-resistance gene $(a m p R)$ and the oriC region of $M$. imitans. The ampR gene was amplified from pGEM-T using the AmpRfor and AmpRrev primer pair, and the partial oriC region of $M$. imitans was amplified using the SW15for and Misojrev-1 primer pair (Table 1), together with the products radiolabelled as described above. The hybridization and washing conditions were the same as those used for the oriC probe.

Targeted gene inactivation by homologous recombination using oriC plasmids. To construct an oriC plasmid that could integrate into a target gene by homologous recombination, an internal fragment of the vlhA3.03 gene (which also has $96 \%$ DNA identity with vlhA1.1 and vlhA1.2 of M. gallisepticum strain S6), including regions that diverged significantly from most other vlhA genes, was amplified from the genome of M. gallisepticum strain $\mathrm{R}_{\text {low }}$ using the P3.03-F-PstI and P3.03-R-SalI primer pair or the P3.03-FSphI and P3.03-R-NcoI primer pair (Table 1). The PCR products were digested with the appropriate restriction endonucleases and cloned separately into the PstI and SalI restriction sites in pPLoriC7, which contained $180 \mathrm{bp}$ of the $M$. gallisepticum oriC region, and into the
$S p h \mathrm{I}$ and $\mathrm{NcoI}$ restriction sites in the M. imitans oriC plasmid pMIori (Fig. 3). Approximately $10 \mu \mathrm{g}$ of these plasmids was introduced into $M$. gallisepticum strain S6 by electroporation, as described above. Seven days after electroporation, individual tetracycline-resistant colonies were selected from the agar plate and incubated in $500 \mu \mathrm{l}$ medium containing $4 \mu \mathrm{g}$ tetracycline $\mathrm{ml}^{-1}$ until a colour change was observed in the medium. The cultures were then screened for the presence of the tetM gene by PCR. To promote homologous recombination, each transformant was passaged 10 times in medium containing tetracycline, and then an additional five times without tetracycline. Transformants were spread on agar containing tetracycline and individual tetracycline-resistant colonies were selected 7 days after plating. Insertion of the construct into vlhA3.03 was assessed by Southern blotting. The genomic DNA from transformants and plasmid DNA were digested with PstI (New England Biolabs) and Southern-transferred. The membrane was hybridized to radiolabelled $a m p R$ and the amplified fragment of vlhA3.03, and binding of the probes was detected as described above. The integration of pMIori/ $\Delta 3.03$ was confirmed by DNA sequencing of the PCR product that was obtained using the primer pair SW13 for and vlhALeader rev (Table 1).

\section{RESULTS}

\section{Functional analysis of $M$. gallisepticum oriC plasmids for $M$. gallisepticum, $M$. imitans and $M$. pneumoniae}

Several oriC plasmids containing different extents of the putative oriC region of $M$. gallisepticum were produced and investigated for their ability to replicate in M. gallisepticum strain S6. The pGTLori plasmid contained a $1.96 \mathrm{~kb}$ region upstream of the soj gene, which included three DnaA boxes and four AT-rich clusters; the pGTSori plasmid contained a $0.64 \mathrm{~kb}$ DNA region downstream from the soj gene, which included two DnaA boxes but no AT-rich cluster; and pGTDori contained both the $1.96 \mathrm{~kb}$ region upstream and the $0.64 \mathrm{~kb}$ region downstream from the soj gene, which was replaced in the plasmid by the tet $M$ gene. The pGTWori plasmid contained the $3.16 \mathrm{~kb}$ putative oriC region, including the soj gene (Fig. 1a). All plasmid constructs were introduced into M. gallisepticum strain S6 by electroporation and all, with the exception of
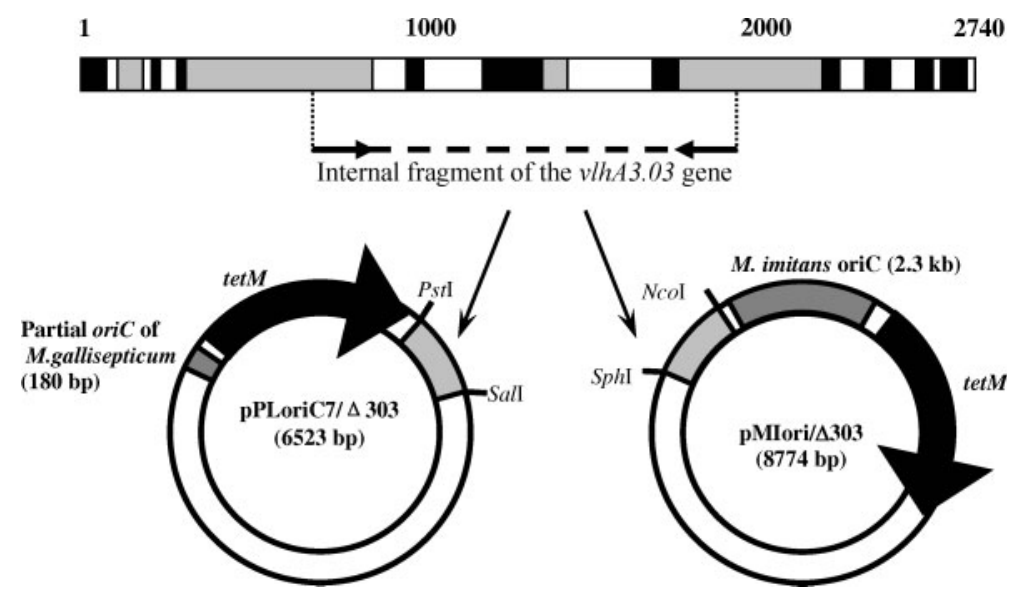

Fig. 3. Schematic representation of alignment of the vlhA multigene family and plasmid constructs containing an internal part of the vlhA3.03 gene. Black rectangles indicate regions of conserved DNA, grey rectangles indicate regions of variable DNA sequence and white rectangles indicate regions of highly variable DNA sequence; results were obtained through DNA sequence alignment of the vlhA multigene family. The amplified internal part of the vlhA3.03 gene was cloned separately into the Pstl and Sall restriction sites in pPLoriC7 and into the Sphl and Ncol restriction sites in the $M$. imitans oriC plasmid pMlori. 
pGTSori, could be detected in cultures of tetracyclineresistant transformants; the frequency of transformation was $\sim 6 \times 10^{-7}$ transformants per c.f.u. These results suggested that the AT-rich regions were important for plasmid replication, and in addition that the $d n a A$ and $s o j$ genes were not essential for the replication of the oriC plasmid. In order to determine the replicability of the oriC plasmid of M. gallisepticum in M. imitans strain 4229 and M. pneumoniae strain $\mathrm{FH}$, plasmid pGTLori, harbouring a $1.96 \mathrm{~kb}$ region from oriC of $M$. gallisepticum, was introduced into $M$. imitans and $M$. pneumoniae by electroporation. Seven days after transformation, several tetracycline-resistant $M$. imitans colonies were observed on mycoplasma agar plates containing $4 \mu \mathrm{g}$ tetracycline $\mathrm{ml}^{-1}$, but no tetracycline-resistant colonies of $M$. pneumoniae were detected up to 21 days of incubation, in spite of repeated attempts to introduce pGTLori into M. pneumoniae strain $\mathrm{FH}$.

\section{The minimal functional oric region in M. gallisepticum}

Previous studies have reported that oriC plasmids containing larger oriC regions can easily integrate into the oriC region of genomic DNA through homologous recombination after in vitro passage (Cordova et al., 2002; Lartigue et al., 2002; Renaudin et al., 1995). In order to reduce the likelihood of this, a number of plasmids containing different lengths of the oriC region were tested for replication in M. gallisepticum. We amplified the partial ori $\mathrm{C}$ regions (oriC1 to oriC9) (Fig. 2) using specific primer pairs (Table 1) and cloned the products into tetM/pGEM$\mathrm{T}$, and these plasmids were then used to transform $M$. gallisepticum strain S6. Following transformation, the constructs pPLoriC1, pPLoriC3, pPLoriC5, pPLoriC6 and pPLroiC7, but not pPLoriC2, pPLoriC4, pPLoriC8 or pPLoriC9, were able to replicate in M. gallisepticum (Fig. 2 ). These results suggested that the minimal oriC region that was functional in $M$. gallisepticum strain S6 was around $180 \mathrm{bp}$ and included two DnaA boxes and two ATrich regions.

\section{Determination of the DNA sequence of the oric region in, and development of an oriC plasmid from, M. imitans}

Part of the oriC region and the $d n a A$ gene of $M$. imitans were amplified using the corresponding M. gallisepticum primer pairs. PCR products and the remainder of the oriC region were sequenced. The $2.17 \mathrm{~kb}$ region upstream from the soj gene of $M$. imitans contained six DnaA boxes, which had a 9 nt consensus sequence (5'-TTWTMHAMA-3'), and was $90 \% \mathrm{~A}+\mathrm{T}$ (Fig. 1b). Alignment of the oriC regions of M. imitans and M. gallisepticum strain R revealed $56 \%$ DNA sequence identity, whilst their $d n a A$ genes had $85 \%$ DNA sequence identity. The pMIori plasmid contained the $2.3 \mathrm{~kb}$ region upstream from the soj gene (Fig. 1b). The pMIori plasmid was introduced into $M$. imitans strain 4229 and M. gallisepticum strain S6 by electroporation and was found to replicate in both species.

\section{Stability of M. gallisepticum oriC plasmids in M. gallisepticum and $M$. imitans}

We investigated the stability of oriC plasmids in transformants by Southern blot analysis after repeated passage. DNA was extracted from cells of transformants after passaging and, together with the genomic DNA of the untransformed organism and the oriC plasmid purified from E. coli, was digested with NsiI; the fragments were separated by gel electrophoresis, Southern-blotted and hybridized to the appropriate radiolabelled probe. Following NsiI digestion, the M. gallisepticum oriC probe is predicted to bind to an extrachromosomal plasmid with a predicted size of $7.0 \mathrm{~kb}$ (Fig. 4a). The $1.96 \mathrm{kbp}$ oriC probe bound a $3.9 \mathrm{~kb}$ fragment in M. gallisepticum strain S6 (Fig. 4b, lane 1) and to a $7 \mathrm{~kb}$ fragment in pGTLori transformants (Fig. 4b, lane 2); a similar-sized fragment was also detected after five passages of the transformants (Fig. 4b, lane 3). The detection of 4.8 and $6 \mathrm{~kb}$ fragments by the probe at the 10th passage (Fig. $4 \mathrm{~b}$, lane 4 ) indicated integration of the plasmid into the genome in the oriC region. In transformants obtained with pPLoriC1, which contained a $1.06 \mathrm{~kb}$ oriC region, the oriC probe hybridized to the $4.5 \mathrm{~kb}$ fragment predicted for an extrachromosomal plasmid (Fig. 4b, lanes 5 and 6). The detection of 3.4 and $4.8 \mathrm{~kb}$ fragments at the 10th passage indicated that the plasmid had integrated into the genome (Fig. 4b, lane 7). To determine the stability of pPLoriC7, the replicative plasmid containing the shortest section of the oriC region, we performed Southern blot analysis on two transformants passaged under antibiotic selection pressure $(4 \mu \mathrm{g}$ tetracycline $\mathrm{ml}^{-1}$ ) after 5,10 and 15 passages. Due to the low sensitivity of the oriC probe for the $180 \mathrm{nt}$ oriC region, a longer probe that detects the $a m p R$ gene, which would indicate the location of the oriC plasmid, was used. It was expected that the probe would not hybridize to DNA from untransformed M. gallisepticum but would hybridize with a $3.5 \mathrm{~kb}$ DNA fragment after Nsil digestion of the DNA extracted from transformants containing extrachromosomal plasmid, whilst hybridization to a $4.0 \mathrm{~kb}$ fragment would suggest that the plasmid had integrated into the chromosome (Fig. 5a). The probe did not hybridize to untransformed M. gallisepticum (Fig. 5b, lane 1), but bound to a $3.5 \mathrm{~kb}$ fragment derived from the oriC plasmid, and to a similar-sized band in both transformants at the fifth passage (Fig. 5b, lanes 2, 3 and 6). At the 10th passage a $4.0 \mathrm{~kb}$ fragment was detected in all clones, but extrachromosomal plasmid was also detected (Fig. 5b, lanes 4 and 7). By the 15th passage, extrachromosomal plasmid could not be detected and the plasmid appeared to have integrated into the chromosome of each transformant (Fig. 5b, lanes 5 and 8 ). One possible reason for the integration of pPLoriC7 was the selection pressure exerted by the antibiotic. To investigate if this was the cause, we passaged both parental M. gallisepticum and a transformant 
(a)

oriC region of the $M$. gallisepticum genome

pGTLori
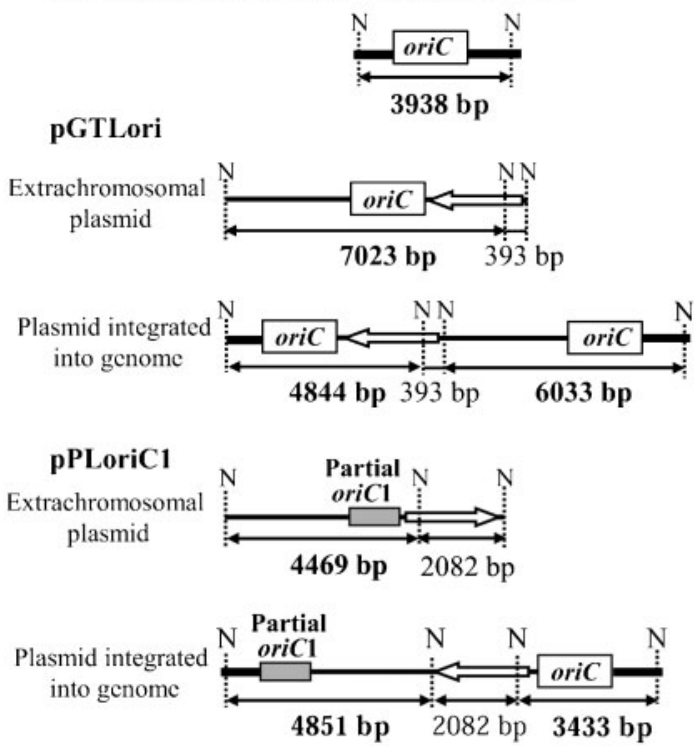

(b)

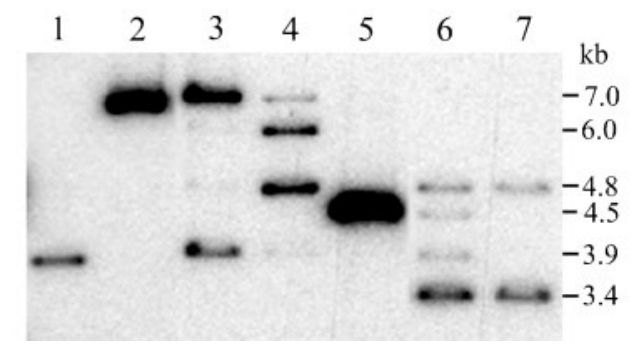

Fig. 4. Stability of oriC plasmids in M. gallisepticum. (a) Schematic diagram showing the Nsil $(\mathrm{N})$ cleavage sites in the extrachromosomal plasmid and the predicted integrated forms of pGTLori and pPLoriC1 in the M. gallisepticum chromosome. The predicted sizes of fragments generated by $N$ sil cleavage that are expected to hybridize with the radiolabelled oriC probe are shown in bold type. The unshaded arrow indicates the tetM gene. (b) Southern blot analysis of Nsil-digested DNA. Lanes: 1, untransformed M. gallisepticum; 2, pGTLori; 3 and 4, M. gallisepticum transformed with pGTLori after 5 and 10 passages, respectively; 5 , pPLoriC1; 6 and 7, M. gallisepticum transformed with pPLoriC1 after 5 and 10 passages, respectively.

containing pPLoriC7 in broth containing tetracycline at 0.4 or $1 \mu \mathrm{g} \mathrm{ml}^{-1}$. Parental M. gallisepticum could only grow in broth containing $0.4 \mu \mathrm{g}$ tetracycline $\mathrm{ml}^{-1}$. Neither extrachromosomal nor integrated forms of the plasmid could be detected in the transformant after five passages in media containing $0.4 \mu \mathrm{g}$ tetracycline $\mathrm{ml}^{-1}$, suggesting that $0.4 \mu \mathrm{g}$ tetracycline $\mathrm{ml}^{-1}$ was an inadequate concentration to select for transformants. In the transformant grown in $1 \mu \mathrm{g}$ tetracycline $\mathrm{ml}^{-1}$, pPLoriC7 had completely integrated into the genome by the 15 th passage. There appeared to be no difference in the rate of integration of (a)

oriC region of the $M$. gallisepticum genome

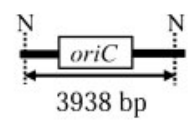

pPLoriC7

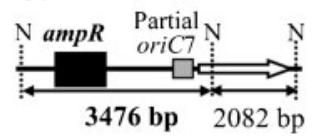

Predicted $\mathrm{oriC}$ region after vector integration

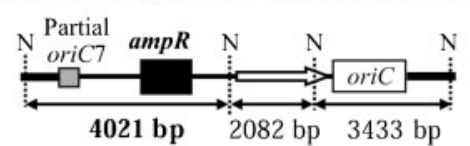

(b)

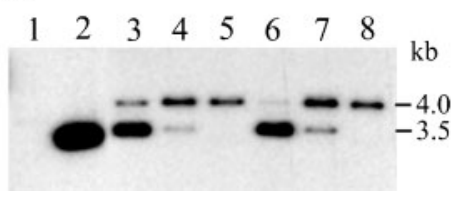

Fig. 5. Stability of the plasmid pPLoriC7, containing a $180 \mathrm{bp}$ oriC region, in $M$. gallisepticum. (a) Schematic representation of the integration of pPLoriC7 into the M. gallisepticum genome. The predicted sizes of fragments generated by Nsil cleavage that would hybridize with the radiolabelled ampR probe are shown in bold type. The unshaded arrow indicates the tetM gene. (b) Southern blot analysis of Nsil-digested DNA. Lanes: 1, untransformed M. gallisepticum strain S6; 2, pPLoriC7; 3-8, fifth, 10th and 15th passages of M. gallisepticum clones 1 (lanes 3-5) and 2 (lanes 6-8) transformed with pPLoriC7.

the plasmid into the chromosome in transformants cultured in low concentrations of tetracycline, suggesting that antimicrobial selection pressure did not influence the rate of chromosomal integration. The stability of pGTLori was tested in two transformants of M. imitans strain 4229, which were selected on solid media containing $4 \mu \mathrm{g}$ tetracycline $\mathrm{ml}^{-1}$ and then passaged 15 times in broth with tetracycline. Southern blot analysis was performed at the fifth, 10th and 15th passages of each transformant using the radiolabelled $M$. gallisepticum oriC probe. The oriC probe did not hybridize with the oriC region of untransformed $M$. imitans (results not shown). At all passage levels examined, a $7 \mathrm{~kb}$ DNA band, indicative of the extrachromosomal form of pGTLori, was detectable in both transformants (results not shown).

\section{Stability of $M$. imitans oriC plasmids in M. gallisepticum and M. imitans}

The oriC plasmid pMIori replicated in both M. gallisepticum strain S6 and M. imitans strain 4229. The stability of this oriC plasmid was investigated following passage of 
transformants. NsiI-digested DNA was hybridized with the radiolabelled $2 \mathrm{~kb} M$. imitans oriC probe, which contained part of the oriC region and the soj gene. A $3.5 \mathrm{~kb}$ band indicative of the genomic oriC region of $M$. imitans was detected in untransformed $M$. imitans and all passaged transformants (Fig. 6a, lanes 2-8). At the 15th passage the $7.4 \mathrm{~kb}$ extrachromosomal form of plasmid was still detectable in both transformants (Fig. 6a, lanes 5 and 8). In M. gallisepticum, the oriC probe, which contained part of the M. imitans soj gene, hybridized to a $3.9 \mathrm{~kb}$ band containing the M. gallisepticum soj gene (Fig. 6b, lane 2). A $7.4 \mathrm{~kb}$ band, corresponding to the extrachromosomal plasmid, was detectable until the 15th passage in transformant C1 (Fig. 6b, lane 5). However, the plasmid had integrated into the genome by the 10th passage, although not into the oriC region (Fig. 6b, lanes 4, 5, 7 and 8).

\section{Targeted inactivation of a gene by homologous recombination using oriC plasmids}

pPLoriC7/ $\Delta 3.03$-transformed M. gallisepticum S6 produced several tetracycline-resistant colonies after 7 days of incubation. To investigate the integration site of the plasmid, Southern blot analysis was performed using DNA extracted from 16 pPLoriC7/ $\Delta 3.03$ transformants that had been passaged 15 times. Identical membranes were

(a)

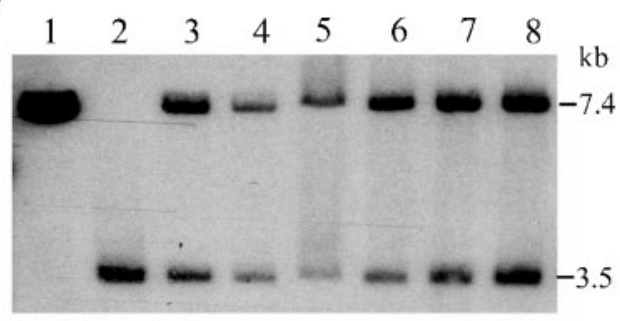

(b)

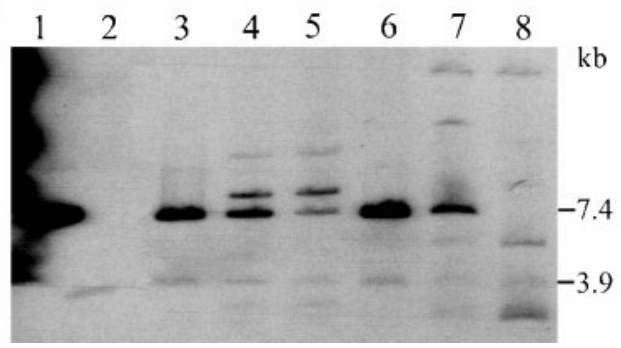

Fig. 6. Stability of oriC plasmid pMlori in M. gallisepticum and $M$. imitans. (a) Southern blot analysis with Nsil-digested DNA hybridized with $a m p R$ radiolabelled probe. Lanes: 1, pMlori; 2, untransformed $M$. imitans strain 4229; 3-8, fifth, 10th and 15th passages of M. imitans clones 1 (lanes 3-5) and 2 (lanes 6-8) of pMlori transformants. (b) Southern blot analysis with Nsil-digested DNA. Lanes: 1, pMlori; 2, untransformed $M$. gallisepticum strain S6; 3-8, 5th, 10th and 15th passages of clones 1 (lanes 3-5) and 2 (lanes $6-8$ ) of M. gallisepticum transformed with pMlori. hybridized to the radiolabelled $a m p R$ gene or the internal fragment of the $v l h A 3.03$ gene. The $a m p R$ probe bound to a $6.5 \mathrm{~kb}$ band in the digest of the plasmid pPLoriC7/ $\Delta 3.03$ and in most passaged transformants to a $10.5 \mathrm{~kb}$ band, corresponding to the predicted size of the fragment containing the chromosomal oriC region of M. gallisepticum S6 after the plasmid had integrated into this region. However, no band indicative of targeted homologous recombination was detected (results not shown).

Tetracycline-resistant colonies of the pMIori/ $\Delta 3.03$ transformants of M. gallisepticum S6 were passaged 15 times and the integration site of the plasmid was investigated by hybridizing Southern blots with radiolabelled ampR gene and vlhA3.03 probes. Several bands were detected in all passaged transformants, indicating that the plasmid had integrated at least twice into the M. gallisepticum genome. The vlhA3.03 probe detected bands of a different size in one of the transformants. This transformant was passaged an additional five times in media that did not contain tetracycline, to allow the transformant to cure itself of the extrachromosomal plasmid, and then inoculated onto mycoplasma agar containing $4 \mu \mathrm{g}$ tetracycline $\mathrm{ml}^{-1}$. Two single tetracycline-resistant colonies were selected for Southern blot analysis. The $a m p R$ probe detected an $8.77 \mathrm{~kb}$ band in the digest of pMIori/ $\Delta 3.03$, while an $\sim 15 \mathrm{~kb}$ band was detected in these transformants (Fig. 7 lanes $\mathrm{P}, 2$ and 3). The gene that was predicted to have been interrupted was amplified using the primer pair SW13 for and vlhALeader rev, generating a PCR product of $\sim 2 \mathrm{~kb}$. DNA sequencing of the PCR product and searches of the databases determined that the amplicon was identical to part of the vlhA1.2 gene (previously $p M G A 1.2$ ) of $M$. galliseptiucm S6 and the section of the vlhA3.03 gene that was contained within the plasmid construct. The product also contained part of the pGEM-T vector. This suggested

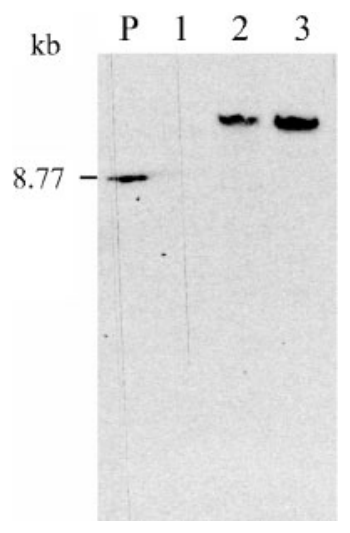

Fig. 7. Integration of pMlori/ $\Delta 3.03$ into the $M$. gallisepticum strain S6 chromosome. Southern blot analysis of Pstl-digested DNA. The blot was hybridized to radiolabelled ampR DNA. Lanes: P, pMlori/ $\Delta 3.03 ; 1$, untransformed M. gallisepticum strain S6; 2 and 3, 20th passage of M. gallisepticum pMlori/ $\Delta 3.03$ transformants 1 and 2, respectively. 
that pMIori/ $\Delta 3.03$ had integrated into the vlhA1.2 gene rather than the vlhA1.1 gene.

\section{DISCUSSION}

In this study, we produced functional oriC plasmids containing the putative oriC regions of $M$. gallisepticum and $M$. imitans. In earlier studies, oriC plasmids have been constructed for Spiroplasma citri, M. mycoides subspecies mycoides LC and SC, M. capricolum subsp. capricolum, Mycoplasma agalactiae and Mycoplasma pulmonis (ChopraDewasthaly et al., 2005; Lartigue et al., 2003). Apart from M. pulmonis, which belongs to the Hominis phylogenic group, all these species belong to the Spiroplasma phylogenic group, and all have a conserved gene order within the oriC region (Fig. 8), which contains the $d n a A$ gene. The functional oriC plasmids for these species require regions upstream and downstream from the dnaA gene, with the exception of the smallest oriC plasmid for S. citri, which contains only a 163 bp region downstream from the dnaA gene (Cordova et al., 2002; Lartigue et al., 2002, 2003). The gene order in the oriC regions of $M$. gallisepticum and $M$. imitans is similar to those of $M$. pneumoniae and Mycoplasma genitalium (Fig. 8). These mycoplasmas belong to the Pneumoniae phylogenetic group and the putative oriC regions surround the soj gene but lie upstream of the $d n a A$ gene (Cordova et al., 2002; Papazisi et al., 2003). We produced four oriC plasmid constructs that contained the soj gene and regions upstream and downstream of the soj gene in $M$. gallisepticum. Only the plasmids containing the region upstream from the soj gene could be detected in $M$. gallisepticum, indicating that only the AT-rich sequences found in this region were essential for plasmid replication, even though the region downstream from the soj gene included two DnaA boxes. This suggests that, at least in $M$. gallisepticum, the soj gene is not required for replication of an oriC plasmid. The $M$. gallisepticum oriC plasmid, pGTLori, and the M. imitans oriC plasmid pMIori were able to replicate in both species. Alignment of the oriC region of M. imitans with that of M. gallisepticum showed that the sequences were very different, but that the surrounding genes had high levels of DNA sequence identity. Both species contained similar DnaA box consensus sequences. Therefore, $M$. gallisepticum and $M$. imitans might be expected to support replication of heterologous oriC plasmids. In contrast to $M$. imitans, $M$. pneumoniae did not appear to support replication of the $M$. gallisepticum oriC plasmid pGTLori. Though both species have a conserved gene order in the oriC region (Fig. 8), the DNA sequence of their oriC regions appears to be poorly conserved, and alignment of the peptide sequence of the DnaA proteins of $M$. gallisepticum and $M$. pneumoniae revealed only $23 \%$ peptide sequence identity. Several ATrich clusters were identified in the putative oriC region of M. pneumoniae, but consensus DnaA box nonamers were not found. This suggests that the DnaA boxes of $M$.
M. gallisepticum

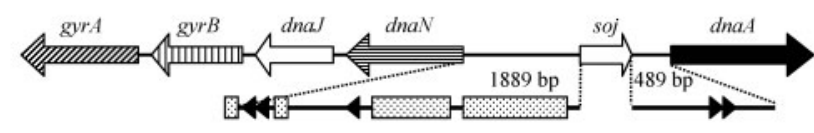

M. imitans

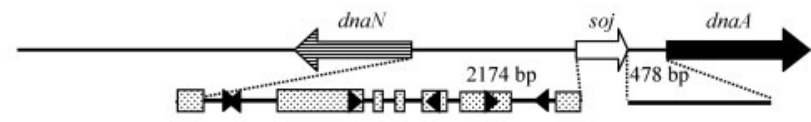

M. pneumoniae

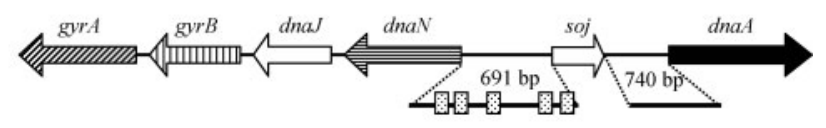

M. genitalium

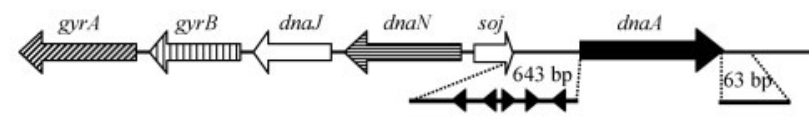

S. citri

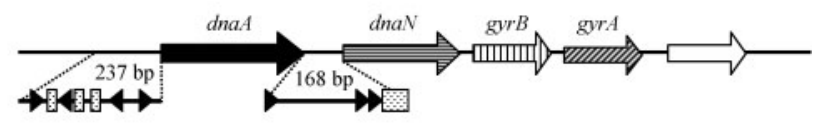

M. capricolum

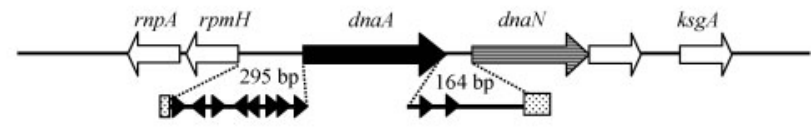

M. pulmonis

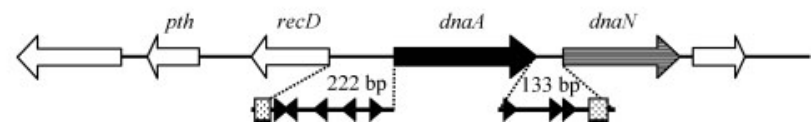

Fig. 8. Gene order surrounding the chromosomal oriC regions of mollicutes and the structure of their putative oriC regions. Triangles indicate the locations of the DnaA box consensus sequences and shaded rectangles indicate the locations of AT-rich regions.

pneumoniae may have a more relaxed consensus sequence. The minimal oriC region of $M$. gallisepticum that was found to be functional in M. gallisepticum strain S6 was $180 \mathrm{bp}$ in size. This region was upstream from the soj gene and included two DnaA boxes and two AT-rich regions of 31 and 22 bases (Fig. 2). The size of the minimal oriC region in $M$. gallisepticum was similar to that required in the functional oriC vector for $S$. citri, which was a $163 \mathrm{bp}$ region downstream from the $d n a A$ gene containing three DnaA boxes and two AT-rich regions (Lartigue et al., 2002). For M. gallisepticum strain S6, we found that only two DnaA boxes were necessary for plasmid replication, and this is the smallest oriC region capable of supporting plasmid replication in mycoplasmas. Both pGTLori and pPLoriC1, which contained larger sections of the oriC 
region, integrated readily into the chromosome during passage, as has been seen with the oriC plasmids pBOT1 in S. citri and pMPO1 in M. pulmonis (Cordova et al., 2002; Renaudin et al., 1995). We produced a smaller oriC plasmid in an attempt to generate a vector that would not integrate readily into the genome. While pPLoriC7 did not integrate into the chromosome as rapidly as pGTLori and pPLoriC1, it had integrated completely into the chromosome by the 15 th passage. In M. pulmonis, the minimal oriC regions necessary for plasmid replication are $262 \mathrm{bp}$ upstream and $327 \mathrm{bp}$ downstream from the dnaA gene. This oriC plasmid (pMPO5) remains extrachromosomal for at least 15 passages (Cordova et al., 2002). The oriC plasmid pGTLori could replicate in M. imitans strain 4229 and appeared to be more stable in M. imitans than in $M$. gallisepticum. In Southern blot analysis, free plasmid was detectable until the 15th passage, with only limited integration into the chromosome. This suggested that the oriC plasmid of $M$. imitans might be more stable in $M$. gallisepticum than the homologous oriC plasmid. However, while some plasmid remained extrachromosomal until the 15th passage, a portion had integrated into the genome at sites outside the oriC region by the 10th passage. Interestingly, an extrachromosomal form of pMIori was found in all passaged transformants of M. imitans. These results suggest that the homologous recombination system in M. gallisepticum has a higher efficiency than that of $M$. imitans.

Targeted gene inactivation was attempted in M. gallisepticum using the pPloriC7 and pMIori plasmids. In a previous study, only five of 16 transformants containing the smallest $S$. citri oriC plasmid (containing $163 \mathrm{bp}$ of the oriC region) had integration of the plasmid into the chromosomal oriC region after 15 passages, and this construct was successfully used to inactivate $s c m 1$ (Lartigue et al., 2002). However, pPLoriC7, containing the $180 \mathrm{bp} \mathrm{M}$. gallisepticum oriC region, integrated readily into the chromosomal oriC region by the 15th passage, and attempts to inactivate vlhA3.03 using pPLoriC7 were unsuccessful, with the plasmid integrating into the chromosomal oriC region in all transformants rather than into the target gene region, even though the vlhA3.03 fragment in the plasmid was $986 \mathrm{bp}$ in size.

Of the $16 \mathrm{M}$. gallisepticum transformants containing pMIori/ $\Delta 3.03$, only one showed evidence of an interruption of a vlhA gene in Southern blot analysis. The inactivated gene was identified as vlhA1.2. At the DNA level, vlhA1.2 and vlhA1.1 are $98 \%$ identical, so this result is not unexpected. Targeted gene inactivation has, to our knowledge, only been achieved once before in $M$. gallisepticum, but use of the $M$. imitans oriC plasmid could improve the efficiency of recombination. Thus, in this study, we constructed several oriC plasmids that could replicate successfully in $M$. gallisepticum and $M$. imitans. This is the first report, to our knowledge, of oriC plasmids for members of the Pneumoniae phylogenetic group. In other mollicutes, oriC plasmids have been used to inactivate genes or to express exogenous genes (Cordova et al., 2002; Duret et al., 1999;
Janis et al., 2005; Lartigue et al., 2002), so these oriC plasmids are likely to be useful tools for genetic research in M. gallisepticum and M. imitans.

\section{ACKNOWLEDGMENTS}

This research was funded by grants from the Australian Poultry Cooperative Research Centre (APCRC) to P.F.M. and G. F. B., and S.-W.L. received an APCRC scholarship. S.-W. L. was also in receipt of an International Postgraduate Research Scholarship and a Melbourne International Research Scholarship.

\section{REFERENCES}

Bearson, S. M., Collier, S. D., Bearson, B. L. \& Branton, S. L. (2003). Induction of a Mycoplasma gallisepticum pMGA gene in the chicken tracheal ring organ culture model. Avian Dis 47, 745-749.

Bradbury, J. M., Abdul-Wahab, O. M., Yavari, C. A., Dupiellet, J. P. \& Bove, J. M. (1993). Mycoplasma imitans sp. nov. is related to Mycoplasma gallisepticum and found in birds. Int J Syst Bacteriol 43, 721-728.

Chopra-Dewasthaly, R., Marenda, M., Rosengarten, R., Jechlinger, W. $\&$ Citti, C. (2005). Construction of the first shuttle vectors for gene cloning and homologous recombination in Mycoplasma agalactiae. FEMS Microbiol Lett 253, 89-94.

Church, G. M. \& Gilbert, W. (1984). Genomic sequencing. Proc Natl Acad Sci U S A 81, 1991-1995.

Cordova, C. M., Lartigue, C., Sirand-Pugnet, P., Renaudin, J., Cunha, R. A. \& Blanchard, A. (2002). Identification of the origin of replication of the Mycoplasma pulmonis chromosome and its use in oriC replicative plasmids. J Bacteriol 184, 5426-5435.

Duret, S., Danet, J. L., Garnier, M. \& Renaudin, J. (1999). Gene disruption through homologous recombination in Spiroplasma citri: an scm1-disrupted motility mutant is pathogenic. J Bacteriol 181, 7449-7456.

Dybvig, K. \& Alderete, J. (1988). Transformation of Mycoplasma pulmonis and Mycoplasma hyorhinis: transposition of Tn916 and formation of cointegrate structures. Plasmid 20, 33-41.

Dybvig, K. \& Cassell, G. H. (1987). Transposition of Gram-positive transposon Tn916 in Acholeplasma laidlawii and Mycoplasma pulmonis. Science 235, 1392-1394.

Glew, M. D., Browning, G. F., Markham, P. F. \& Walker, I. D. (2000). pMGA phenotypic variation in Mycoplasma gallisepticum occurs in vivo and is mediated by trinucleotide repeat length variation. Infect Immun 68, 6027-6033.

Hedreyda, C. T., Lee, K. K. \& Krause, D. C. (1993). Transformation of Mycoplasma pneumoniae with Tn 4001 by electroporation. Plasmid 30, 170-175.

Hudson, P., Gorton, T. S., Papazisi, L., Cecchini, K., Frasca, S., Jr \& Geary, S. J. (2006). Identification of a virulence-associated determinant, dihydrolipoamide dehydrogenase (lpd), in Mycoplasma gallisepticum through in vivo screening of transposon mutants. Infect Immun 74, 931-939.

Janis, C., Lartigue, C., Frey, J., Wroblewski, H., Thiaucourt, F., Blanchard, A. \& Sirand-Pugnet, P. (2005). Versatile use of oriC plasmids for functional genomics of Mycoplasma capricolum subsp. capricolum. Appl Environ Microbiol 71, 2888-2893.

Lartigue, C., Duret, S., Garnier, M. \& Renaudin, J. (2002). New plasmid vectors for specific gene targeting in Spiroplasma citri. Plasmid 48, 149-159. 
Lartigue, C., Blanchard, A., Renaudin, J., Thiaucourt, F. \& SirandPugnet, P. (2003). Host specificity of mollicutes oriC plasmids: functional analysis of replication origin. Nucleic Acids Res 31, 6610-6618.

Ley, D. H. \& Yoder, H. W. J. (1997). Mycoplasma gallisepticum infection. In Diseases of Poultry, pp. 194-207. Edited by B. W. Calnek, H. J. Barnes, C. W. Beard, L. R. McDougald \& Y. M. Saif. London: Mosby-Wolfe.

Mahairas, G. G. \& Minion, F. C. (1989). Random insertion of the gentamicin resistance transposon Tn4001 in Mycoplasma pulmonis. Plasmid 21, 43-47.

Markham, P. F., Glew, M. D., Brandon, M. R., Walker, I. D. \& Whithear, K. G. (1992). Characterization of a major hemagglutinin protein from Mycoplasma gallisepticum. Infect Immun 60, 3885-3891.

Markham, P. F., Kanci, A., Czifra, G., Sundquist, B., Hains, P. \& Browning, G. F. (2003). Homologue of macrophage-activating lipoprotein in Mycoplasma gallisepticum is not essential for growth and pathogenicity in tracheal organ cultures. J Bacteriol 185, 2538-2547.

Marois, C., Dufour-Gesbert, F. \& Kempf, I. (2001). Molecular differentiation of Mycoplasma gallisepticum and Mycoplasma imitans strains by pulsed-field gel electrophoresis and random amplified polymorphic DNA. J Vet Med B Infect Dis Vet Public Health 48, 695-703.

Mudahi-Orenstein, S., Levisohn, S., Geary, S. J. \& Yogev, D. (2003). Cytadherence-deficient mutants of Mycoplasma gallisepticum generated by transposon mutagenesis. Infect Immun 71, 3812-3820.

Papazisi, L., Frasca, S., Jr, Gladd, M., Liao, X., Yogev, D. \& Geary, S. J. (2002). GapA and CrmA coexpression is essential for Mycoplasma gallisepticum cytadherence and virulence. Infect Immun 70, 68396845.

Papazisi, L., Gorton, T. S., Kutish, G., Markham, P. F., Browning, G. F., Nguyen, D. K., Swartzell, S., Madan, A., Mahairas, G. \& Geary, S. J. (2003). The complete genome sequence of the avian pathogen Mycoplasma gallisepticum strain $\mathrm{R}_{\text {low }}$. Microbiology 149, 2307-2316.

Renaudin, J., Marais, A., Verdin, E., Duret, S., Foissac, X., Laigret, F. \& Bove, J. M. (1995). Integrative and free Spiroplasma citri oriC plasmids: expression of the Spiroplasma phoeniceum spiralin in Spiroplasma citri. J Bacteriol 177, 2870-2877.

Sambrook, J. \& Russell, D. W. (2001). Molecular Cloning: a Laboratory Manual, 3rd edn. Cold Spring Harbor, NY: Cold Spring Harbor Laboratory.

Whetzel, P. L., Hnatow, L. L., Keeler, C. L., Jr \& Dohms, J. E. (2003). Transposon mutagenesis of Mycoplasma gallisepticum. Plasmid 49, 34-43.

Whithear, K. G. (1993). Avian mycoplasmosis. In Australian Standard Diagnostic Techniques for Animal Diseases, pp. 1-12. Edited by L. A. Corner \& T. J. Bagust. East Melbourne: Australian Agricultural Council (Standing Committee on Agriculture and Resource Management).

Winner, F., Markova, I., Much, P., Lugmair, A., Siebert-Gulle, K., Vogl, G., Rosengarten, R. \& Citti, C. (2003). Phenotypic switching in Mycoplasma gallisepticum hemadsorption is governed by a highfrequency, reversible point mutation. Infect Immun 71, 1265-1273.

Edited by: C. Citti 